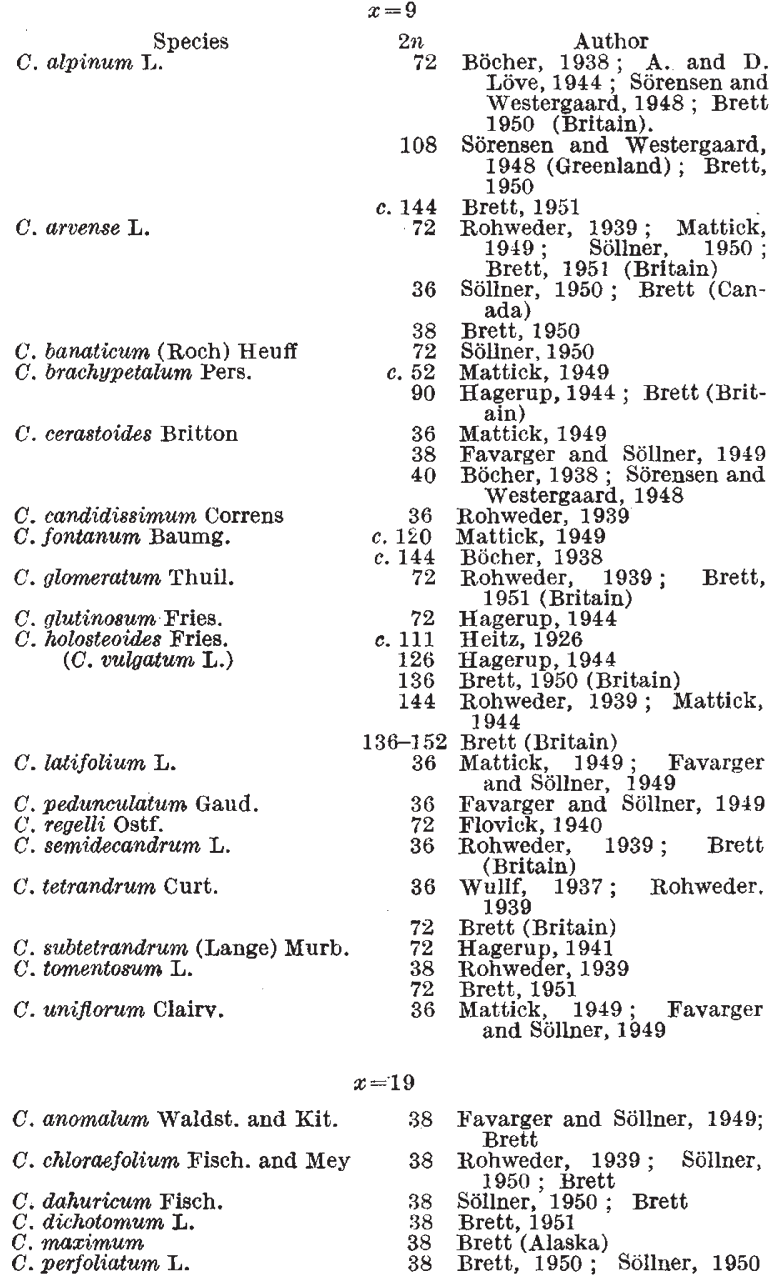

Strephodon species $C$. perfoliatum. It would also appear, as Söllner ${ }^{2}$ has already suggested, that the Dichodon species $C$. anomalum is related to $C$. perfoliatum and, in my opinion, to $C$. dichotomum also. Further investigation it is hoped will result in a more natural classification than that formulated by Seringe and published originally by de Candolle ${ }^{3}$.

Other counts in these lists call for comment. Three species, $C$. cerastoides, $C$. arvense and $C$. tomentosum, appear to have both basic numbers. The morphological and geographical evidence would suggest that they belong to the $x=9$ group and possibly, therefore, the 38 and 40 chromosome members are aneuploids, $4 x+2$ and $4 x+4$.

The species $C$. holosteoides (C.vulgatum) is peculiar in that its chromosome number is not constant even for the offspring of the same plant after selfing. This species is a very high polyploid, probably 16-ploid, and it would seem that, at this degree of ploidy, loss or gain of a few chromosomes at meiosis has little if any effect upon the viability and fertility of the seed. The range of chromosome numbers given as 136-152 is probably wider than this, as approximate counts have been made which indicated even lower and higher numbers. Many multivalents are found at first metaphase, and it is thought that different numbers pass to the poles at first anaphase. Lagging chromosomes, though found, are by no means the rule, and usually all the chromosomes are included in one of the four nuclei at the end of meiosis.

The question of the origin of these two basic numbers remains. It is possible that their origins are quite distinct; but, alternatively, it could be that as a result of hybridization the plants with 38 chromosomes have the activity of all but two of their nucleolar-organizing chromosomes suppressed, the situation being similar to that discovered by Nevashin ${ }^{4}$ in Crepis.

Queen Mary College

(University of London), Mile End Road, London, E.1.

${ }^{1}$ McClintock, B. M., Z. Zellforschung und Mikroskopische Anat., 21, 294 (1934)

2 Söllner, R., Experientia, 6, 335 (1950)

' de Candolle, P. de, "Prodromus Systematis Naturalis regni vegetabilis", pars prima, 414 (1824).

4 Nevashin, M., Cytologia, 5, 169 (1934).

\section{Colonization of Plant Debris by Coprinus Species in Soils}

IsoLATION of members of the group Basidiomycetes, as compared with other soil fungi, directly from soil by either the soil dilution plate ${ }^{1}$ or the root burial technique ${ }^{2}$ has met with little success, though better results have been obtained by the soil plate technique ${ }^{8}$. Hitherto, studies on their distribution were mostly confined to the recording of fructifications (which may be of seasonal occurrence) in Nature ${ }^{4}$. However, in the course of investigations in this laboratory on survival of Macrophomina phaseoli by the root burial technique in Madras garden soil amended with ammonia at different concentrations $(2,5$ and 10 per cent), it was observed that a Basidiomycete regularly colonized and produced fructifications on pieces of cotton root when plated on agar media (potatodextrose and Horne and Mitters's media). The incubation period needed in the soil for this colonization was only two weeks. The control pieces of root buried in untreated soil failed to yield the fungus. This work was extended to cotton-growing soils, namely, Coimbatore, Udamalpet and Kovilpatti soils (Madras State). In all cases similar fructifications were observed only in the soils treated with ammonia. 'This Basidiomycete was also found to colonize and produce its fructifications on pieces of root soaked in 50 per cent ammonia solution for one hour and incubated for one week in the above-mentioned soils. The fungus has been identified as a species of Coprinus.

I am indebted to the Director, Royal Botanic Gardens, Kew, for the identification of the Basidiomycete, and to Prof. T. S. Sadasivan, for help and guidance during this investigation. My thanks are due to the Government of India for the award of a Junior Research Scholarship.

\section{E. J. Chinnayya}

Botanical Laboratory, University

Madras 5.

Feb. 19.

${ }^{1}$ Waksman, S. A., "Principles of Soil Microbiology", 37 (Williams and Wilkins Co., Baltimore, 1932).

Sadasivan, T. S., Ann. App. Biol., 26, 497 (1939). Subramanian, C. V., Proc. Ind. Acad. Sci., B, 81, 67 (1950).

3 Warcup, J. H., Nature, 166, 117 (1950)

4 Parker-Rhodes, A. F., New Phytol., 50, 227 (1951). 